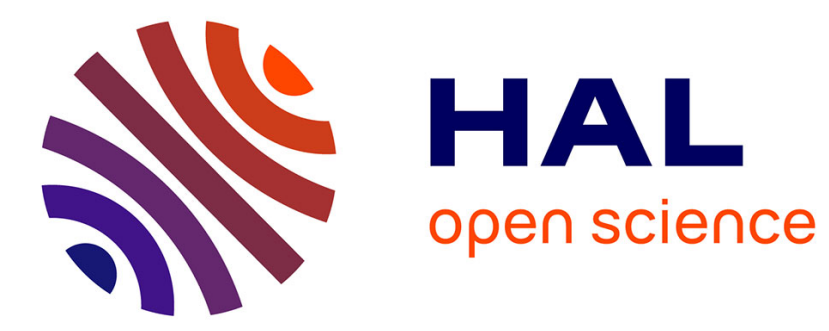

\title{
Cross-relaxation and ion clustering in Tm3+:CaF2 crystals
}

Pavel Loiko, A. Braud, Lauren Guillemot, Jean-Louis Doualan, Abdelmjid Benayad, Patrice Camy

\section{- To cite this version:}

Pavel Loiko, A. Braud, Lauren Guillemot, Jean-Louis Doualan, Abdelmjid Benayad, et al.. Crossrelaxation and ion clustering in Tm3+:CaF2 crystals. SPIE Photonics Europe, Apr 2020, Online Only, France. pp.23, 10.1117/12.2555057 . hal-03140566

\section{HAL Id: hal-03140566 https://hal.science/hal-03140566}

Submitted on 7 Oct 2021

HAL is a multi-disciplinary open access archive for the deposit and dissemination of scientific research documents, whether they are published or not. The documents may come from teaching and research institutions in France or abroad, or from public or private research centers.
L'archive ouverte pluridisciplinaire HAL, est destinée au dépôt et à la diffusion de documents scientifiques de niveau recherche, publiés ou non, émanant des établissements d'enseignement et de recherche français ou étrangers, des laboratoires publics ou privés. 


\title{
Cross-relaxation and ion clustering in $\mathrm{Tm}^{3+}: \mathrm{CaF}_{2}$ crystals
}

\author{
Pavel Loiko ${ }^{\mathrm{a}, *}$, Alain Braud ${ }^{\mathrm{a}}$, Lauren Guillemot ${ }^{\mathrm{a}}$, Jean-Louis Doualan ${ }^{\mathrm{a}}$, Abdelmjid Benayad $^{\mathrm{a}}$, \\ and Patrice Camy \\ ${ }^{a}$ Centre de recherche sur les Ions, les Matériaux et la Photonique (CIMAP), UMR 6252 CEA- \\ CNRS-ENSICAEN, Université de Caen, 6 Boulevard du Maréchal Juin, 14050 Caen, France
}

\begin{abstract}
We systematically study cross-relaxation (CR) and ion clustering in $\mathrm{Tm}^{3+}: \mathrm{CaF}_{2}$ crystals using a spectroscopic approach. For this, the luminescence from the ${ }^{3} \mathrm{H}_{4}$ and ${ }^{3} \mathrm{~F}_{4}$ states was monitored for a broad range of $\mathrm{Tm}^{3+}$ doping concentrations, from 0.01 at.\% to 7 at.\%. The decay curves were fitted using a model of two ions classes, namely isolated ions showing no energy-transfer processes and ions with neighbors exhibiting both CR and energy-transfer upconversion (ETU), and accounting for energy-migration. The fraction of ions with neighbors and the microscopic concentration-independent CR and ETU parameters are deduced. The critical $\mathrm{Tm}^{3+}$ doping level for which at least half of the active ions are clustered is only 0.7 at.\%. The obtained results are relevant for achieving efficient laser operation of $\mathrm{Tm}^{3+}: \mathrm{CaF}_{2}$ crystals at the ${ }^{3} \mathrm{~F}_{4} \rightarrow$ ${ }^{3} \mathrm{H}_{6}($ at $\sim 1.9 \mu \mathrm{m})$ and the ${ }^{3} \mathrm{H}_{4} \rightarrow{ }^{3} \mathrm{H}_{5}$ (at $\left.\sim 2.3 \mu \mathrm{m}\right)$ transitions.
\end{abstract}

Keywords: calcium fluoride, thulium ions, cross-relaxation, ion clustering, luminescence.

\section{INTRODUCTION}

Cubic (fluorite-type) calcium fluoride $\left(\mathrm{CaF}_{2}\right)$ crystals are well-known for fabrication of optical elements because of their good thermo-mechanical properties (thermal conductivity: $\kappa \sim 9.7 \mathrm{~W} /(\mathrm{mK})$ for an undoped crystal), broad transparency range $(0.13-10 \mu \mathrm{m})$ and low refractive index $(n=1.424$ at $\sim 2 \mu \mathrm{m}) . \mathrm{CaF}_{2}$ crystals are also suitable for doping with trivalent rare-earth ions $\left(\mathrm{RE}^{3+}\right)$ for laser applications [1-3]. They feature a strong $\mathrm{RE}^{3+}$ ion clustering even at low doping concentrations about $0.1-1$ at.\% [4,5] resulting in broad and smooth spectral bands both in absorption and emission (the so-called glassy-like spectroscopic behavior). It is of interest for broadly tunable [6] and mode-locked [7,8] lasers. The good thermal properties of the host matrix allow for power scaling.

Thulium $\left(\mathrm{Tm}^{3+}\right.$ ) doped $\mathrm{CaF}_{2}$ crystals exhibit a broadband emission at $\sim 1.9 \mu \mathrm{m}$ due to the ${ }^{3} \mathrm{~F}_{4} \rightarrow{ }^{3} \mathrm{H}_{6}$ electronic transition. Efficient $\mathrm{Tm}^{3+}: \mathrm{CaF}_{2}$ lasers were reported [2,9]. Camy et al. reported on a laser-pumped $\mathrm{Tm}: \mathrm{CaF}_{2}$ laser delivering $\sim 135$ $\mathrm{mW}$ at $1887 \mathrm{~nm}$ with a slope efficiency of $41 \%$ and a laser threshold of only $68 \mathrm{~mW}$ [2]. Liu et al. reported on power scaling of a Tm: $\mathrm{CaF}_{2}$ laser under diode-pumping yielding $2.71 \mathrm{~W}$ with a higher slope efficiency of $70.1 \%$ [9]. The same group of authors demonstrated continuous wavelength tunability for this laser between 1.85 and $2.04 \mu \mathrm{m}(189 \mathrm{~nm}$ broad $)$ and mode-locked operation employing a SESAM. In the latter case, 15 ps-long pulses were obtained at a central wavelength of $1886.8 \mathrm{~nm}$ with a repetition rate of $96.35 \mathrm{MHz}$ [9]. Thin films of Tm:CaF2 were grown [10].

It was proven that the ion clustering determines the emission properties of $\mathrm{Tm}^{3+}$ ions in $\mathrm{CaF}_{2}$ [5]. For low doping levels (0.01-0.1 at.\%), the $\mathrm{Tm}^{3+}$ ions are mostly isolated and they accommodate in sites with different symmetry depending on the charge compensation mechanism involving interstitial $\mathrm{F}^{-}$anions. For higher doping levels, ion clusters are formed. To prevent the clustering of active ions, the $\mathrm{CaF}_{2}$ crystals were codoped by $\mathrm{Tm}^{3+}$ ions and optically passive "buffer" ions $\mathrm{Ln}^{3+}$ such as $\mathrm{Gd}^{3+}, \mathrm{Lu}^{3+}, \mathrm{La}^{3+}$ or $\mathrm{Y}^{3+}[11,12]$. Laser operation with such codoped crystals was also demonstrated. Zhang et al. reported on a Tm, $\mathrm{La}: \mathrm{CaF}_{2}$ laser delivering $4.27 \mathrm{~W}$ at $1921 \mathrm{~nm}$ with a slope efficiency of $67.8 \%$ [12].

A key spectroscopic process which determines the laser efficiency of $\sim 1.9 \mu \mathrm{m}$ Tm lasers is the cross-relaxation (CR) for adjacent $\mathrm{Tm}^{3+}$ ions, ${ }^{3} \mathrm{H}_{4}\left(\mathrm{Tm}_{1}\right)+{ }^{3} \mathrm{H}_{6}\left(\mathrm{Tm}_{2}\right) \rightarrow{ }^{3} \mathrm{~F}_{4}\left(\mathrm{Tm}_{1}\right)+{ }^{3} \mathrm{~F}_{4}\left(\mathrm{Tm}_{2}\right)$, potentially leading to a pump quantum efficiency of 2 [13]. This means that after an excitation at $\sim 0.8 \mu \mathrm{m}$ (to the ${ }^{3} \mathrm{H}_{4}$ pump level), there can be up to 2 excited ions in the upper laser level $\left({ }^{3} \mathrm{~F}_{4}\right)$. CR in $\mathrm{Tm}^{3+}$-doped laser materials increases the laser slope efficiency and reduces the heat dissipation. Up to now, no detailed study of CR for $\mathrm{Tm}: \mathrm{CaF}_{2}$ crystals was performed.

\footnotetext{
*e-mail: pavel.loiko@ensicaen.fr
} 
The aim of the present work is to study the cross-relaxation (and other energy-transfer processes, such as energy-transfer upconversion (ETU)) in $\mathrm{Tm}: \mathrm{CaF}_{2}$ crystals accounting for the ion clustering. For this, we involve the spectroscopic model of distinct ion classes which was recently developed [14].

\section{EXPERIMENTAL RESULTS}

For the spectroscopic studies, we grew a series of $\mathrm{Tm}^{3+}: \mathrm{CaF}_{2}$ crystals with the doping level ranging from 0.01 at. $\%$ to 7 at. $\%$. The Tm: $\mathrm{CaF}_{2}$ crystals were grown using a conventional Bridgman technique with a homemade furnace. A mixture of high purity $(4 \mathrm{~N}) \mathrm{CaF}_{2}$ and $\mathrm{TmF}_{3}$ powders was introduced in a graphite crucible. A good vacuum $\left(<10^{-5}\right.$ mbar $)$ was realized before introducing $\mathrm{Ar}$ and $\mathrm{CF}_{4}$ gases to avoid oxygen pollution. The furnace temperature was set to about $50 \mathrm{~K}$ higher than the melting point of $\mathrm{CaF}_{2}$. After soaking, the charge was thoroughly melted and the crystal growth was carried out with a rate of 2-4 mm/h. When the growth was finished, the crystal was cooled down to room temperature (RT, $293 \mathrm{~K}$ ) within 48 hours.

\subsection{Absorption and luminescence}

The RT absorption spectra of $\mathrm{Tm}^{3+}: \mathrm{CaF}_{2}$ crystals containing predominantly isolated ions $(0.05$ at. $\% \mathrm{Tm})$ and ion clusters (1.5 at.\% and 4.5 at.\% $\mathrm{Tm}$ ) are shown in Fig. 1. It is known that in $\mathrm{Tm}^{3+}$-doped $\mathrm{CaF}_{2}$ crystals with very low doping levels, the active ions are distributed over three types of sites with the symmetry $\mathrm{C}_{3 \mathrm{v}}$ (trigonal), $\mathrm{C}_{4 \mathrm{v}}$ (tetragonal) or $\mathrm{O}_{\mathrm{h}}$ (cubic). The particular symmetry depends on the charge compensation mechanism (as trivalent $\mathrm{Tm}^{3+}$ ions are replacing the divalent $\mathrm{Ca}^{2+}$ ones). The latter is provided by an interstitial fluorine anion $\left(\mathrm{F}_{\mathrm{i}}^{-}\right)$. Here, we do not consider the possible charge compensation by oxygen $\left(\mathrm{O}^{2-}\right)$ or univalent alkali metal cations $\left(\mathrm{Na}^{+}, \mathrm{K}^{+}\right)$leading to other types of sites. As a result, the absorption spectra of the 0.05 at. $\% \mathrm{Tm}^{3+}: \mathrm{CaF}_{2}$ crystal represent a superposition of sharp absorption lines of $\mathrm{Tm}^{3+}$ ions in all three sites. For high doping levels, the $\mathrm{Tm}^{3+}$ ions are mostly arranged in clusters leading to smooth and broad spectral bands. There is no significant change in the absorption spectra of 1.5 at.\% Tm and 4.5 at.\% Tm-doped crystals, except of the ${ }^{3} \mathrm{H}_{6} \rightarrow{ }^{3} \mathrm{H}_{5}$ transition. The small changes may reflect the transition from simple clusters (dimers, trimers) to large agglomerates of active ions.
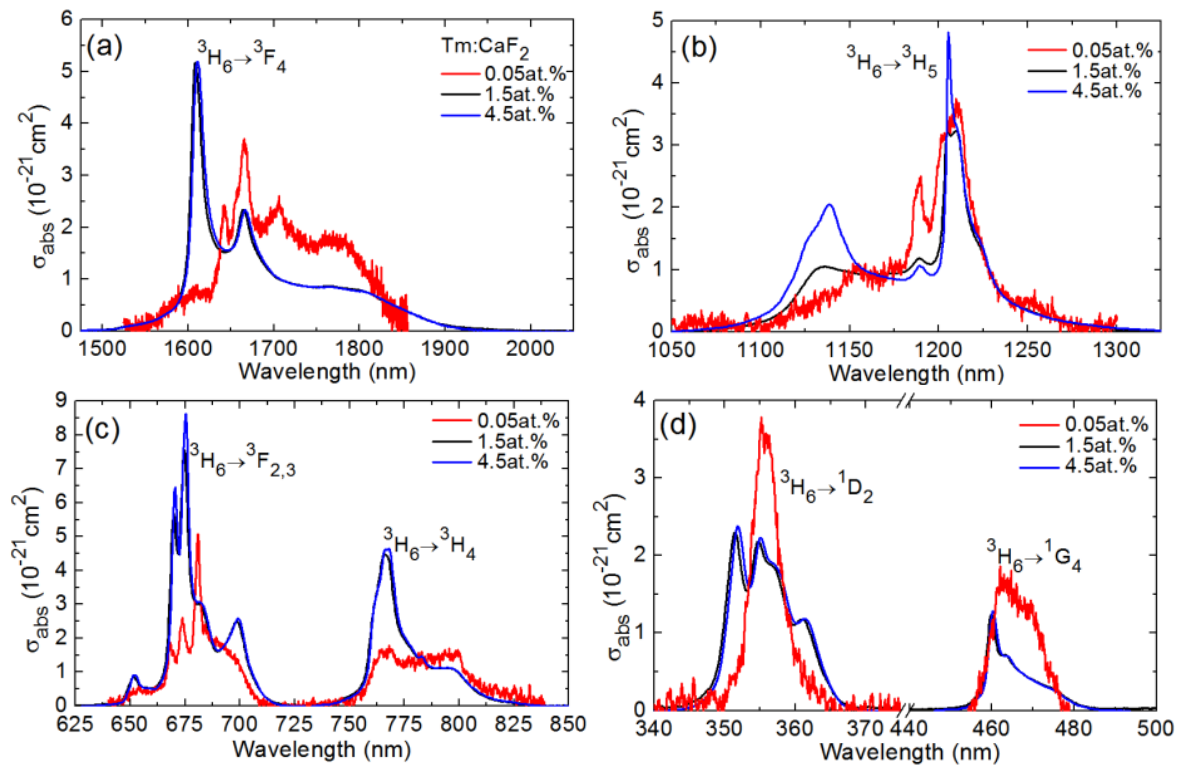

Figure 1. RT absorption cross-section, $\sigma_{\mathrm{abs}}$, spectra of $\mathrm{Tm}^{3+}: \mathrm{CaF}_{2}$ crystals with different Tm doping concentrations $(0.05$ at.\%, 1.5 at.\% and 4.5 at.\%): transitions from the ground-state $\left({ }^{3} \mathrm{H}_{6}\right)$ to the excited-states: (a) ${ }^{3} \mathrm{~F}_{4}$, (b) ${ }^{3} \mathrm{H}_{5}$, (c) ${ }^{3} \mathrm{H}_{4}$ and ${ }^{3} \mathrm{~F}_{2,3}$, and (d) ${ }^{1} \mathrm{G}_{4}$ and ${ }^{1} \mathrm{D}_{2}$.

For the ${ }^{3} \mathrm{H}_{6} \rightarrow{ }^{3} \mathrm{H}_{4}$ pump transition, the maximum absorption cross-section $\sigma_{\text {abs }}$ is $0.46 \times 10^{-20} \mathrm{~cm}^{2}$ at $766.2 \mathrm{~nm}$ and the full width at half maximum (FWHM) of the absorption band is $13.2 \mathrm{~nm}$ (for the 4.5 at.\% Tm doping). For the 0.05 at.\% Tm doping, the peak $\sigma_{\mathrm{abs}}$ value is much lower, $0.17 \times 10^{-20} \mathrm{~cm}^{2}$ at $\sim 768 \mathrm{~nm}$. 
The evolution of RT luminescence spectra for the ${ }^{3} \mathrm{H}_{4} \rightarrow{ }^{3} \mathrm{H}_{6}$ (at $\sim 0.8 \mu \mathrm{m}$ ) and ${ }^{3} \mathrm{~F}_{4} \rightarrow{ }^{3} \mathrm{H}_{6}$ (at $\sim 1.9 \mu \mathrm{m}$ ) transitions in emission was studied for a broad range of Tm doping concentrations $(0.01-7$ at.\%). This comparative study revealed a critical Tm concentration (0.5-0.7 at.\%) for which a significant change in the shape of the emission bands is observed: the spectra become smooth and broad and they resemble to a great extent those for $\mathrm{Tm}^{3+}$-doped fluoride glasses. This is an indication of a change in the predominant ion coordination (a transition from isolated ions to clusters). Figure 2 shows such a comparison for the emission from the pump level $\left({ }^{3} \mathrm{H}_{4}\right)$ at $\sim 0.8 \mu \mathrm{m}$.

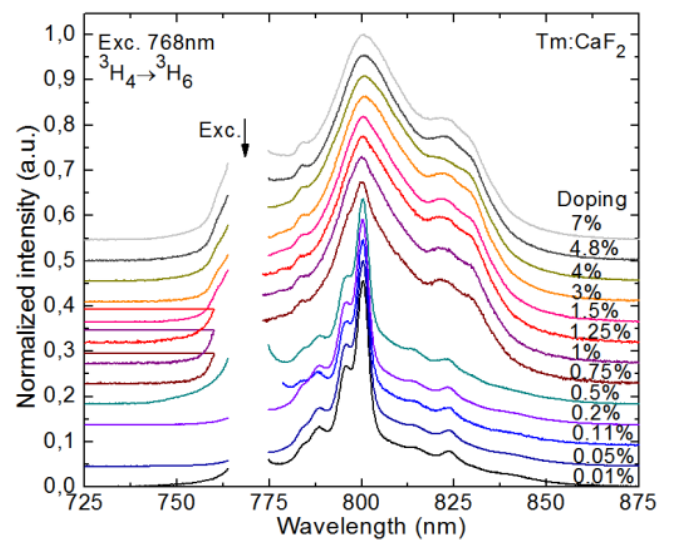

Figure 2. Normalized RT luminescence spectra of $\mathrm{Tm}^{3+}: \mathrm{CaF}_{2}$ crystals with different doping concentrations (the ${ }^{3} \mathrm{H}_{4} \rightarrow{ }^{3} \mathrm{H}_{6}$ transition), $\lambda_{\mathrm{exc}}=769 \mathrm{~nm}$ (non-selective excitation).

\subsection{Luminescence decay}

We monitored the decay of $\mathrm{Tm}^{3+}$ luminescence from the ${ }^{3} \mathrm{H}_{4}$ and ${ }^{3} \mathrm{~F}_{4}$ multiplets for a broad range of $\mathrm{Tm}$ doping levels (0.01-7 at.\%) in $\mathrm{CaF}_{2}$. Figure 3 shows the measured luminescence decay curves for the ${ }^{3} \mathrm{H}_{4} \rightarrow{ }^{3} \mathrm{H}_{6}$ transition in emission (at $\sim 0.8 \mu \mathrm{m}$ ). For very low doping level $(0.01$ at. $\% \mathrm{Tm}$ ), the luminescence decay curve is close to a single-exponential one with a characteristic lifetime $\tau_{\text {lum }}$ of $3.55 \mathrm{~ms}$. Despite the existence of several species contributing to this emission (namely, isolated $\mathrm{Tm}^{3+}$ ions in various sites), the intrinsic lifetimes of the ${ }^{3} \mathrm{H}_{4}$ state for the $\mathrm{C}_{3 \mathrm{v}}$ and $\mathrm{C}_{4 \mathrm{v}}$ coordinated $\mathrm{Tm}^{3+}$ ions in $\mathrm{CaF}_{2}$ are rather close: $3.03 \mathrm{~ms}$ and $3.59 \mathrm{~ms}$, respectively (as determined in site-selective excitation experiments). With increasing Tm doping, the decay from the ${ }^{3} \mathrm{H}_{4}$ state becomes faster and the luminescence decay curves notably deviate from the single-exponential law.

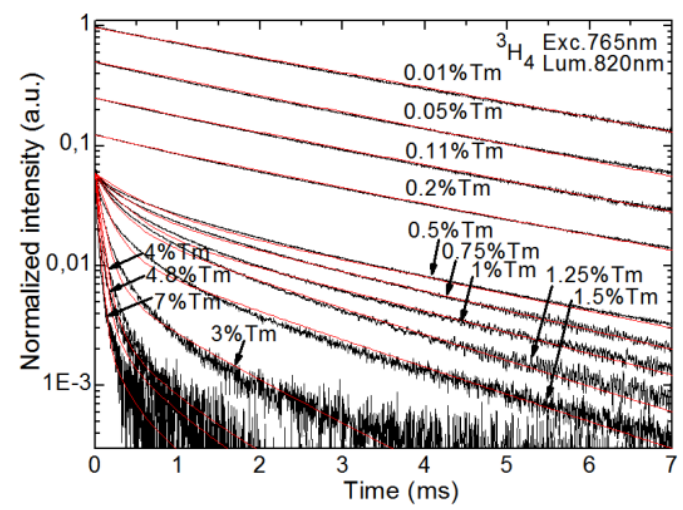

Figure 3. Luminescence decay curves from the ${ }^{3} \mathrm{H}_{4} \mathrm{Tm}^{3+}$ state in $\mathrm{Tm}^{3+}: \mathrm{CaF}_{2}$ : black - experimental data, red - their fitting with the rate-equation model of distinct ion classes, $\lambda_{\mathrm{exc}}=765 \mathrm{~nm}, \lambda_{\text {lum }}=820 \mathrm{~nm}$. Measured under ns pulse excitation.

To explain this behavior, we used the model of spectroscopically distinct ion classes [14]. A simplified scheme of $\mathrm{Tm}^{3+}$ energy-levels was considered, Fig. 4 . The populations of the $\mathrm{Tm}^{3+}$ ground-state $\left({ }^{3} \mathrm{H}_{6}\right)$ and two relevant excited-states $\left({ }^{3} \mathrm{~F}_{4}\right.$ and ${ }^{3} \mathrm{H}_{4}$ ) were monitored; the population of the intermediate ${ }^{3} \mathrm{H}_{5}$ excited-state was assumed to be almost zero as this state is depopulated by very efficient multi-phonon non-radiative (NR) relaxation. The states above ${ }^{3} \mathrm{H}_{4}$ were not taken into account. The following spectroscopic processes were considered: (i) radiative (R) decay from the ${ }^{3} \mathrm{~F}_{4}$ and ${ }^{3} \mathrm{H}_{4}$ states, (ii) cross-relaxation (CR) ${ }^{3} \mathrm{H}_{4}\left(\mathrm{Tm}_{1}\right)+{ }^{3} \mathrm{H}_{6}\left(\mathrm{Tm}_{2}\right) \rightarrow{ }^{3} \mathrm{~F}_{4}\left(\mathrm{Tm}_{1}\right)+{ }^{3} \mathrm{~F}_{4}\left(\mathrm{Tm}_{2}\right)$, (iii) energy-transfer upconversion, ${ }^{3} \mathrm{~F}_{4}\left(\mathrm{Tm}_{1}\right)+$ 
${ }^{3} \mathrm{~F}_{4}\left(\mathrm{Tm}_{2}\right) \rightarrow{ }^{3} \mathrm{H}_{6}\left(\mathrm{Tm}_{1}\right)+{ }^{3} \mathrm{H}_{4}\left(\mathrm{Tm}_{2}\right)\left(\mathrm{ETU}_{1}\right)$ and ${ }^{3} \mathrm{~F}_{4}\left(\mathrm{Tm}_{1}\right)+{ }^{3} \mathrm{~F}_{4}\left(\mathrm{Tm}_{2}\right) \rightarrow{ }^{3} \mathrm{H}_{6}\left(\mathrm{Tm}_{1}\right)+{ }^{3} \mathrm{H}_{5}\left(\mathrm{Tm}_{2}\right)\left(\mathrm{ETU}_{2}\right)$, and (iv) energymigration (EM) to impurities leading to de-excitations from the ${ }^{3} \mathrm{~F}_{4}$ and ${ }^{3} \mathrm{H}_{4}$ multiplets. We assumed the existence of two distinct ion classes: (a) isolated ions showing no energy-transfer processes (CR and ETU) and (b) ions with neighbors exhibiting both CR and ETU. The fraction of ions with neighbors $f$, the macroscopic rates of CR $\left(W_{\mathrm{CR}}\right)$ and ETU ( $W_{\mathrm{ETU} 1}$ and $W_{\text {ETU2 }}$ ) and the ${ }^{3} \mathrm{H}_{4}$ level lifetime $\tau_{3}$ accounting for EM were used as free parameters of the fitting (for luminescence decay curves shown in Fig. 3). The model gives a satisfactory agreement with the experiment.

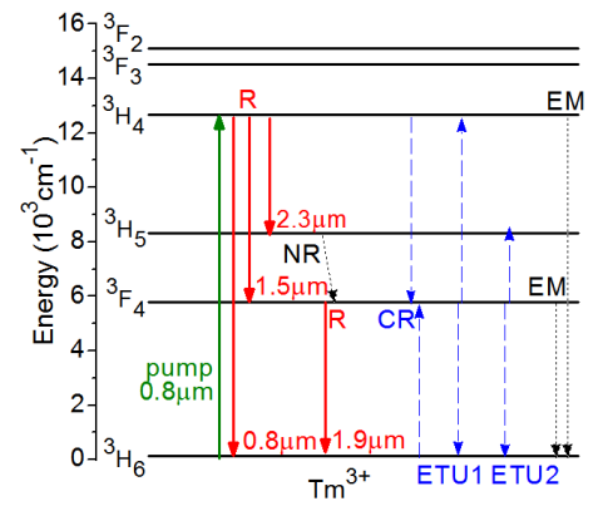

Figure 4. The scheme of energy-levels of $\mathrm{Tm}^{3+}$ ions (for a free-ion) showing relevant spectroscopic processes associated with the conventional pumping scheme (to the ${ }^{3} \mathrm{H}_{4}$ state): $\mathrm{R}$ - radiative relaxation, $\mathrm{NR}$ - multiphonon non-radiative relaxation, CR - cross-relaxation, ETU - energy-transfer upconversion, EM - energy-migration.

\section{DISCUSSION}

The results on the fraction of $\mathrm{Tm}^{3+}$ ions with neighbors $f$ are shown in Fig. 5. With increasing the Tm doping level, the fraction of isolated ions $(1-f)$ gradually decreases. The critical Tm doping level for which at least half of the active ions are clustered is only $0.7 \pm 0.1$ at.\%. This agrees well with our conclusion drawn from the measured luminescence spectra at $\sim 0.8 \mu \mathrm{m}$. The dependence of $f$ on the doping concentration was fitted using a statistical approach $[14,15]$ :

$$
P_{m, n}=\frac{n !}{m !(n-m) !} p^{m}(1-p)^{n-m}
$$

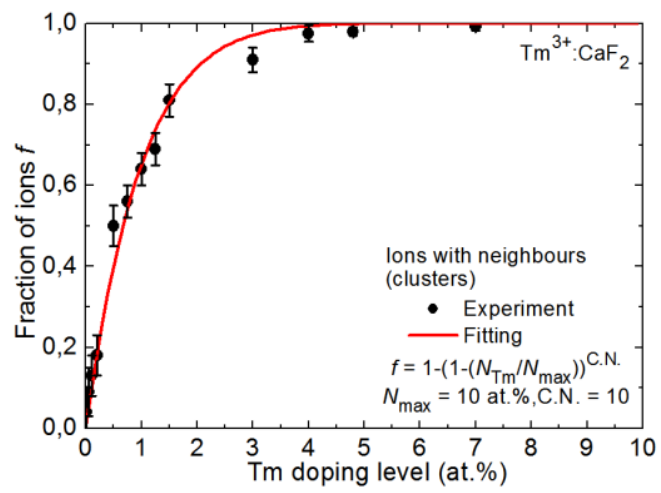

Figure 5. Ion clustering in $\mathrm{Tm}^{3+}: \mathrm{CaF}_{2}$ : fraction of ions with neighbors $f$, symbols - data extracted from the modeling of the experimental luminescence decay curves using the rate-equation model of distinct ion classes, curve - their fit using a statistical approach.

Here, $P_{\mathrm{m}, \mathrm{n}}$ is the probability for occurrence of neighbor $\mathrm{Tm}^{3+}$ ions in the first coordination sphere of the considered $\mathrm{Tm}^{3+}$ ion, $n$ is the coordination number (C.N.) by nearest-neighbor rare-earth sites, $m$ is the actual number of $\mathrm{Tm}^{3+}$ ions in the first coordination sphere ( $m=0$ corresponds to a single ion and $m \geq 1$ - to an ion pair or cluster), and $p=N_{\mathrm{Tm}} / N_{\max }$ represents the relative doping concentration ( $N_{\max }$ is the maximum possible concentration). The expression for the fraction of ions with neighbors ( $m \geq 1$, not specifying the exact $m$ number) is: 


$$
f=1-\left[1-\left(N_{\mathrm{Tm}} / N_{\max }\right)\right]^{\mathrm{C} . \mathrm{N} .} .
$$

For calculation, we assume $N_{\max }=10$ at. $\%$ and C.N. $=10$ which gives a good agreement with the data obtained from the measured luminescence curves.

The model also yields the macroscopic rates $W_{\mathrm{CR}}, W_{\mathrm{ETU} 1}$ and $W_{\mathrm{ETU} 2}$ [in s ${ }^{-1}$ ], as shown in Fig. 6 . The $\mathrm{CR}$ is Tm:CaF 2 is much stronger than the ETU. $W_{\mathrm{CR}}$ and $W_{\mathrm{ETU} 1(2)}$ show a quadratic dependence on the Tm doping concentration $\left(N_{\mathrm{Tm}}\right)$ :

$$
\begin{gathered}
W_{\mathrm{CR}}=C_{\mathrm{CR}} N_{\mathrm{Tm}}{ }^{2}, \\
W_{\mathrm{ETU} 1(2)}=C_{\mathrm{ETU} 1(2)} N_{\mathrm{Tm}}{ }^{2},
\end{gathered}
$$

where $C_{\mathrm{CR}}$ and $C_{\mathrm{ETU1}}$ (2) are the concentration-independent microscopic energy-transfer parameters. $\mathrm{CR}$ in $\mathrm{Tm}^{3+}: \mathrm{CaF}_{2}$ is about one order of magnitude stronger than that in other well-known fluoride crystal, $\mathrm{Tm}^{3+}: \mathrm{LiYF}_{4}[16]$.

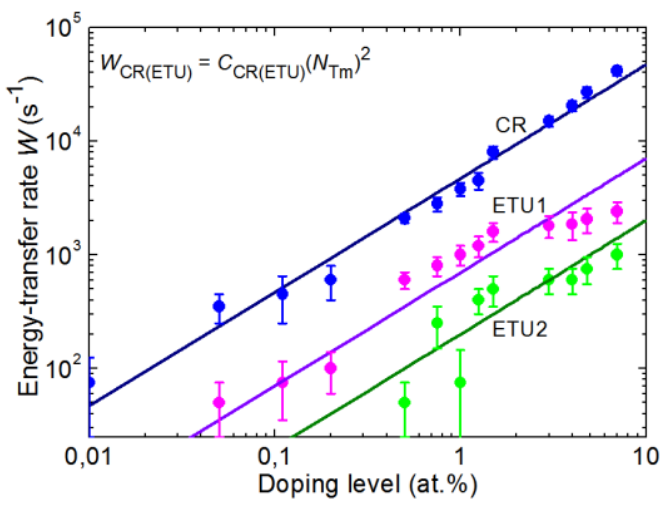

Figure 6. Energy-transfer processes in $\mathrm{Tm}^{3+}: \mathrm{CaF}_{2}$ : macroscopic rates of cross-relaxation $(\mathrm{CR}) W_{\mathrm{CR}}$ and energy-transfer upconverison (ETU) $W_{\mathrm{ETU}(2)}$, symbols - data extracted from the modeling of the experimental luminescence decay curves using the rate-equation model of distinct ion classes, lines - their quadratic fits.

\section{CONCLUSIONS}

To conclude, we have quantified ion clustering (in terms of fraction of ions with neighbors) and CR and ETU energytransfer processes (in terms of macroscopic rates and microscopic concentration-independent parameters) in $\mathrm{Tm}^{3+}$-doped $\mathrm{CaF}_{2}$ crystals, for the first time, to the best of our knowledge. This information is of key importance for the design of Tm: $\mathrm{CaF}_{2}$ lasers operating on the ${ }^{3} \mathrm{~F}_{4} \rightarrow{ }^{3} \mathrm{H}_{6}(\sim 1.9 \mu \mathrm{m})$ and ${ }^{3} \mathrm{H}_{4} \rightarrow{ }^{3} \mathrm{H}_{5}(\sim 2.3 \mu \mathrm{m}[17])$ transitions. Indeed, for the $\sim 1.9 \mu \mathrm{m}$ lasers, quantification of $\mathrm{CR}$ is important to determine the possibility to reach high pump quantum efficiency of 2 for the upper laser level $\left({ }^{3} \mathrm{~F}_{4}\right)$ [13]. For the $\sim 2.3 \mu \mathrm{m}$ lasers which have not been demonstrated yet in $\mathrm{Tm}: \mathrm{CaF}_{2}$, in contrast, $\mathrm{CR}$ is a detrimental effect as it quenches the lifetime of the upper laser level $\left({ }^{3} \mathrm{H}_{4}\right)$. However, ETU1 in such lasers can play a key role in refilling the ${ }^{3} \mathrm{H}_{4}$ state leading to increased laser slope efficiency [16,18]. The proposed spectroscopic model can be extended to describe the ion clustering in $\mathrm{Tm}^{3+}, \mathrm{Ln}^{3+}: \mathrm{CaF}_{2}$ crystals codoped with "buffer" ions.

\section{ACKNOWLEDGEMENTS}

This work was supported by the Agence Nationale de la Recherche (ANR), SPLENDID2 Project; European Community funds FEDER; Normandie region, NOVAMAT Project.

\section{REFERENCES}

[1] F. Druon, S. Ricaud, D. N. Papadopoulos, A. Pellegrina, P. Camy, J. L. Doualan, R. Moncorgé, A. Courjaud, E. Mottay, and $\mathrm{P}$. Georges, "On $\mathrm{Yb}: \mathrm{CaF}_{2}$ and $\mathrm{Yb}: \mathrm{SrF}_{2}$ : review of spectroscopic and thermal properties and their impact on femtosecond and high power laser performance," Opt. Mater. Express 1(3), 489-502 (2011).

[2] P. Camy, J.L. Doualan, S. Renard, A. Braud, V. Menard, and R. Moncorgé, "Tm ${ }^{3+}: \mathrm{CaF}_{2}$ for $1.9 \mu \mathrm{m}$ laser operation," Opt. Commun. 236(4-6), 395-402 (2004). 
[3] Labbe, C., Doualan, J.L., Camy, P., Moncorgé, R. and Thuau, M., "The $2.8 \mu \mathrm{m}$ laser properties of $\mathrm{Er}^{3+} \mathrm{doped}^{\mathrm{CaF}} 2$ crystals," Opt. Commun. 209(1-3), 193-199 (2002).

[4] V. Petit, P. Camy, J.-L. Doualan, X. Portier, and R. Moncorgé, "Spectroscopy of $\mathrm{Yb}^{3+}: \mathrm{CaF}_{2}$ : from isolated centers to clusters," Phys. Rev. B Condens. Matter Mater. Phys. 78(8), 085131 (2008).

[5] S. Renard, P. Camy, A. Braud, J. L. Doualan, and R. Moncorgé, " $\mathrm{CaF}_{2}$ doped with $\mathrm{Tm}^{3+}$ : A cluster model," J. Alloys Compd. 451(1-2), 71-73 (2008).

[6] A. Lucca, M. Jacquemet, F. Druon, F. Balembois, P. Georges, P. Camy, J. L. Doualan, and R. Moncorgé, "Highpower tunable diode-pumped $\mathrm{Yb}^{3+}: \mathrm{CaF}_{2}$ laser," Opt. Lett. 29(16), 1879-1881 (2004).

[7] A. Lucca, G. Debourg, M. Jacquemet, F. Druon, F. Balembois, P. Georges, P. Camy, J. L. Doualan, and R. Moncorgé, "High-power diode-pumped $\mathrm{Yb}^{3+}: \mathrm{CaF}_{2}$ femtosecond laser," Opt. Lett. 29(23), 2767-2769 (2004).

[8] Friebel, F., Druon, F., Boudeile, J., Papadopoulos, D.N., Hanna, M., Georges, P., Camy, P., Doualan, J.L., Benayad, A., Moncorgé, R. and Cassagne, C., "Diode-pumped 99 fs Yb:CaF 2 oscillator," Opt. Lett. 34(9), 1474-1476 (2009).

[9] Liu, J., Zhang, C., Zhang, Z., Wang, J., Fan, X., Liu, J. and Su, L., "1886-nm mode-locked and wavelength tunable Tm-doped $\mathrm{CaF}_{2}$ lasers," Opt. Lett. 44(1), 134-137 (2019).

[10] Brasse, G., Loiko, P., Grygiel, C., Leprince, P., Benayad, A., Lemarie, F., Doualan, J.L., Braud, A. and Camy, P., "Liquid Phase Epitaxy growth of $\mathrm{Tm}^{3+}$-doped $\mathrm{CaF}_{2}$ thin-films based on $\mathrm{LiF}$ solvent," J. Alloys Compd. 803, 442449 (2019).

[11] X. Liu, K. Yang, S. Zhao, T. Li, C. Luan, X. Guo, B. Zhao, L. Zheng, L. Su, J. Xu, and J. Bian, "Growth and lasing performance of a Tm,Y:CaF 2 crystal," Opt. Lett. 42(13), 2567-2570 (2017).

[12]Zhang, Z., Guo, X., Wang, J., Zhang, C., Liu, J. and Su, L., "High-efficiency $2 \mu \mathrm{m}$ continuous-wave laser in laser diode-pumped $\mathrm{Tm}^{3+}, \mathrm{La}^{3+}: \mathrm{CaF}_{2}$ single crystal," Opt. Lett. 43(17), 4300-4303 (2018).

[13] K. van Dalfsen, S. Aravazhi, C. Grivas, S. M. García-Blanco, and M. Pollnau, "Thulium channel waveguide laser with 1.6 W of output power and $\sim 80 \%$ slope efficiency," Opt. Lett. 39(15), 4380-4383 (2014).

[14]P. Loiko, and M. Pollnau, "Stochastic model of energy-transfer processes among rare-earth ions. Example of $\mathrm{Al}_{2} \mathrm{O}_{3}: \mathrm{Tm}^{3+}$, , J. Phys. Chem. C 120(46), 26480-26489 (2016).

[15] Voron'ko, Y.K., Mamedov, T.G., Osiko, V.V., Timoshechkin, M.I. and Shcherbakov, I.A., "Effect of donor-donor and donor-acceptor interactions on the decay kinetics of the metastable state of $\mathrm{Nd}^{3+}$ in crystals," Sov. J. Exp. Theor. Phys. 38, 565 (1974).

[16] Loiko P., Soulard R., Guillemot L., Brasse G., Doualan J.L., Braud A., Tyazhev A., Hideur A., Druon F., and Camy P., "Efficient Tm:LiYF 4 lasers at $2.3 \mu \mathrm{m}$ : Effect of energy-transfer upconversion," IEEE J. Quantum Electron. 55(6), $1700212(2019)$.

[17] Pinto J. F., Esterowitz L., and Rosenblatt G. H., "Tm ${ }^{3+}$ :YLF laser continuously tunable between 2.20 and $2.46 \mu \mathrm{m}$," Opt. Lett. 19(12), 883-885 (1994).

[18] Guillemot L., Loiko P., Soulard R., Braud A., Doualan J.L., Hideur A., and Camy P., "Close look on cubic $\mathrm{Tm}: \mathrm{KY}_{3} \mathrm{~F}_{10}$ crystal for highly efficient lasing on the ${ }^{3} \mathrm{H}_{4} \rightarrow{ }^{3} \mathrm{H}_{5}$ transition," Opt. Express 28(3), 3451-3463 (2020). 